\title{
Urea salvage in a neonate with cloacal exstrophy
}

\author{
R A Wheeler, D M Griffiths, A A Jackson
}

\begin{abstract}
Urea kinetics were measured in a child with congenital absence of the colon on days 15, 19, and 23 of age. Urea salvage was $5 \%$ of urea production in the first study, increasing to $79 \%$ by the third. This provides evidence that the colonic microflora play a more active part in urea salvage than the mucosa and that the establishment of an active lower ileal microflora takes over some of the metabolic functions of the intact colon. (Arch Dis Child 1993; 69: 83-84)
\end{abstract}

In normal individuals a proportion of the urea produced is salvaged for further metabolic interaction. ${ }^{1}$ In infancy the urea in the mother's milk or formula contributes to the body's metabolic pool of nitrogen. ${ }^{2}$ Urea nitrogen is salvaged for metabolism through the metabolic activity of the colonic microflora. In neonates, the ability to salvage urea nitrogen is established shortly after birth, even in infants on total parenteral nutrition. ${ }^{34}$ It was of interest to measure the extent to which urea nitrogen was salvaged in an infant with a congenital absence of the colon.

\section{Patient and methods}

A girl of 34 weeks' gestation was referred at birth with the diagnosis of cloacal exstrophy (vitello intestinal fissure). At corrective surgery on the third day of life it was confirmed that the colonic sinus was only $2 \mathrm{~cm}$ in length with complete absence of the remainder of the large bowel. The defect in the abnormal wall was repaired, and ureterostomies and a terminal ileostomy were fashioned. Prophylactic antibiotics were given for five days postoperatively. She managed with intravenous fluids perioperatively and received her mother's milk from about 10 days of age.

Metabolic studies were carried out at the age of 15,19 , and 23 days. Urea kinetics were measured as previously described. ${ }^{34}$ Briefly, a prime $(0.625 \mathrm{mg} / \mathrm{kg}$ ) and continuous intragastric infusion $(0.0625 \mathrm{mg} / \mathrm{kg} / \mathrm{hour})$ of ${ }^{15} \mathrm{~N}^{15} \mathrm{~N}$ urea (97.7 atoms \%, MSD Isotopes), were given for 14 hours. Urine was collected from a stoma bag sited over the ureterostomy by continuous aspiration onto ice. A sample of urine was collected before the administration of any isotope for the measurement of background enrichment then samples were taken every four hours during the isotope infusion. Urea was assayed in urine and isolated for the measurement of the enrichment in urea nitrogen by isotope ratio mass spectrometry. The levels of plateau enrichment in urinary urea were used to determine the rates of urea production and the recycling of salvaged urea nitrogen to urea formation.

\section{Results}

The clinical features of the subject and the results of the urea kinetics are shown in the table. At the first study the infant had been off antibiotics for seven days. Three studies were carried out over eight days, during which the metabolic state was stable and weight unchanged. Urea production (that is, appearance includes that in the diet) changed little between studies at 15, 19, and 23 days: 60,54 , and $81 \mathrm{mg}$ nitrogen $/ \mathrm{kg} /$ day respectively. In contrast, urinary excretion decreased progressively from 57 to $17 \mathrm{mg}$ nitrogen $/ \mathrm{kg} /$ day by the third study. Hence salvaged urea increased from $3 \mathrm{mg}$ nitrogen $/ \mathrm{kg} /$ day or $5 \%$ of production, in the first study of $64 \mathrm{mg}$ nitrogen $/ \mathrm{kg} /$ day, or $79 \%$ of production, by the third study.

\section{Discussion}

In earlier studies we had found that urea salvage was already established by a few days of age, even in infants on total parenteral nutrition who had never had a dietary intake. ${ }^{23}$ In contrast, urea salvage was virtually absent in the subject in the present study, born without a colon. Significant salvage of urea nitrogen was evident only around the third week of life and is probably indicative of the establishment of a functional microflora in the lower ileum associated with the ileostomy. In the past there has been controversy about both the site of urea hydrolysis and the extent to which mucosal urease activity unrelated to a bacterial flora might be of importance. In the germ free rat there was no hydrolysis of urea. ${ }^{5}$ Our results provide supportive evidence for the suggestion that all urea hydrolysis is bacterial in origin, rather than mucosal.

In the present study about $80 \%$ of the urea produced was salvaged. Although this may appear to be considerable it does conform to

Clinical characteristics of the patient at the time of the three studies and the values derived for urea kinetics

\begin{tabular}{|c|c|c|c|}
\hline & \multicolumn{3}{|l|}{ Study } \\
\hline & 1 & 2 & 3 \\
\hline Age (days) & 15 & 19 & 23 \\
\hline Weight $(\mathrm{g})$ & 1930 & 1890 & 1920 \\
\hline Days after operation/antibiotics & $12 / 7$ & $16 / 11$ & $20 / 15$ \\
\hline Blood urea $(\mathrm{mmol} / \mathrm{l})$ & 6.7 & $5 \cdot 2$ & $5 \cdot 5$ \\
\hline Haemoglobin $(g / 1)$ & 124 & 142 & 134 \\
\hline \multicolumn{4}{|c|}{ Urea kinetics (mg nitrogen $/ \mathrm{kg} /$ day) } \\
\hline Produced & 60 & 54 & 81 \\
\hline Excreted & 57 & 47 & 17 \\
\hline Salvaged & 3 & 7 & 64 \\
\hline Recycled & 0 & 0 & 8 \\
\hline Utilised & 3 & 7 & 56 \\
\hline Salvaged/produced (\%) & 5 & 13 & 79 \\
\hline
\end{tabular}

Correspondence to: Mr R A Wheeler, Hospita for Sick Children, Grea WC1 3JH.

Accepted 29 January 1993
Centre for Paediatric

R A Wheele

Department of Human Nutrition, University of Southampton

A A Jackson 
the pattern observed in other infants during the first month of life. ${ }^{3}$ In the present study we were not able to determine the intake of protein or urea in the breast milk, nevertheless it is likely that the salvaged urea nitrogen (equivalent to $0.4 \mathrm{~g}$ protein $/ \mathrm{kg} /$ day) made an important contribution to the overall intake of nitrogen and protein. ${ }^{1}$ The data emphasise the critical role played by the colon and its resident microflora in the process of salvaging urea nitrogen and show that in the absence of a colon some of these functions may be taken over by an established ileostomy.
This work was supported in part by the Rank Foundation, the Rank Prize Funds, the Hedley Foundation, and the Wessex Medical Trust.

1 Danielsen $M$, Jackson AA. Limits of adaptation to a diet low in protein in normal man: urea kinetics. Clin $S_{c i} 1992 ; 83$ : 103-8.

2 Harzer G, Franzke V, Bindels JG. Human milk nonprotein nitrogen components: changing pattern of free amino acids and urea in the course of early lactation. Am 7 Clin Nutr 1984; 40: 303-9.

3 Wheeler RA, Jackson AA, Griffiths DM. Urea production and recycling in neonates. $\mathcal{F}$ Pediatr Surg 1991; 26: 575-7.

4 Wheeler RA, Griffiths DM, Jackson AA. Urea kinetics in Wheeler RA, Griffiths DM, Jackson AA. Urea kinetics in
neonates receiving total parenteral nutrition. Arch Dis Child 1993; 69: 24-7.

5 Levenson SM, Crowley LV, Horowitz RE, Malm OJ. The metabolism of carbon labelled urea in the germ free rat f Biol Chem 1959; 234: 2061-2.

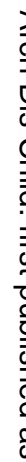

